\title{
ANALISIS STRUKTUR ORGANISASI, SISTEM WEWENANG, PRAKTEK YANG SEHAT, KARYAWAN YANG BERMUTU TERHADAP SISTEM PENGENDALIAN INTERN KAS PT. CITRA VAN TIKI SOLO
}

\author{
Pardi $^{1}$, Alisa Rusdiana ${ }^{2}$ \\ ${ }^{1}$ Akuntansi, Sekolah Tinggi Ilmu Ekonomi Surakarta \\ e-mail : ppardi@stiesurakarta.ac.id \\ ${ }^{2}$ Akuntansi, Sekolah Tinggi Ilmu Ekonomi Surakarta
}

\begin{abstract}
This research was conducted with the aim to knowing the effect of organization structure, system of authority / authorization, healthy practice, and quality employees on the internal cash control system. The approach used in this study is quantitative, using 566 employee population who actively attend monthly meetings at PT. Citra Van Tiki Solo Branch. Samples using the Slovin formula, obtained amounted to 85 people. The data analysis technique used test instruments, namely; validity test, reliability test, normality test, multicollinearity test, heteroscedasticity test, Autocoleration test, multiple linear regression, $F$ test, $t$ test, and determination test $(R 2)$ which were processed using SPSS 21.0 program. The results showed that the organization structure, system of authority, healthy practice, and quality employees partially affected the internal cash control system.
\end{abstract}

Keywords : Organization Structure, System of Authority, Healthy Practice, Quality Employees.

\section{PENDAhULUAN}

Kas memiliki sifat yang sangat liquid, kas sering menjadi sasaran kecurangan atau pencurian sehingga perlu perhatian pengawasan perusahaan. Dalam akuntansi prosedur untuk melindungi kas dari pencurian dan penyalahgunaan sangat penting dilakukan manajemen perusahaan (Al. Yusup, 2011).

Perusahaan pada dasarnya mempunyai prinsip kontinuitas dan kas sangat menentukan kelangsungan hidup perusahaan, terutama dalam membiayai kegiatan operasi perusahaan. Untuk mengamankan kas dan menjamin keakuratan (ketepatan penyajian) atas catatan akuntansi kas, pengendalian internal yang efektif atas kas mutlak dipergunakan guna menghindarkan Perusahaan dari kerugian yang lebih besar (Dewi, dkk. 2017).

Perusahaan memiliki sistem pengendalian dalam mengatur aktivitas usahanya. Pengendalian atas kas sangat penting bagi perusahaan karena sebagian besar transaksi perusahaan terdiri dari pertukaran uang kas. Pengendalian internal yang baik dapat membantu kelancaran operasional perusahaan. Disamping itu dapat diketahui apakah kebijaksanaan yang telah ditetapkan oleh manajemen sudah dijalankan sebagai mestinya, sehingga diharapkan dapat menunjang tercapainya tujuan perusahaan (Dewi, dkk 2017).

Melindungi kas dan menjamin keakuratan catatan akuntansi dalam pengendalian intern yang efektif merupakan suatu keharusan. Pengendalian internal yang baik menghindari terjadinya penyelewengan perusahaan. Perencanaan kas yang baik dapat membantu manajemen dalam mengetahui informasi pemasukan dan pengeluaran kas. Sistem pengendalian intern kas berguna bagi manajer keuangan untuk menilai kinerja yang telah dicapai perusahaan (Purnama, 2015). 
Aktivitas Pengendalian diperlukan untuk mencegak salah saji yang material dalam pengelolaan kas. Pengendalian intern kas umumnya sangat ketat karena jenis aktiva ini mudah digelapkan untuk diselewengkan. Sistem pengendalian internal meliputi struktur organisasi, metode dan ukuran-ukuran yang dikoordinasikan untuk menjaga aset organisasi, mengecek ketelitian dan keandalan data akuntansi, mendorong efisiensi dan mendorong dipatuhinya kebijakan manajemen (Mulyadi, 2016).

Sistem pengendalian intern kas dalam praktik masih ditemukan permasalahan seperti: struktur organisasi terjadi perangkapan fungsi antara bagian kasir dengan bagian akuntansi, hal ini dapat terjadi penyelewengan kas. Tujuan penelitian ini untuk mengetahui pengaruh struktur organisasi, sistem wewenang, praktek yang sehat, dan karyawan yang bermutu sistem pengendalian intern kas. Penelitian ini sangat penting dilakukan untuk efisiensi pengelolaan kas melalui sistem pengendalian intern kas.

\section{LANDASAN TEORI}

\section{Sistem Pengendalian Intern}

Pengendalian intern adalah suatu proses yang dijalankan oleh dewan komisaris, manajemen, dan personil lain, yang didesain untuk memberikan keyakinan memadai tentang pencapaian keandalan pelaporan, kepatuhan peraturan, dan efektivitas-efisiensi operasi (Mulyadi, Kanaka, 2008).

Sistem pengendalian internal meliputi struktur organisasi, metode dan ukuran-ukuran yang dikoordinasikan untuk menjaga aset organisasi, mengecek ketelitian dan keandalan data akuntansi, mendorong efisiensi dan mendorong dipatuhinya kebijakan manajemen (Mulyadi,2016).

Sistem pengendalian intern yang baik dapat mendorong ditetapkannya kebijakan manajemen, terciptanya efisiensi, melindungi aktiva serta menjamin terciptanya data akuntansi yang tepat dan dipercaya (Al. Yusup, 2011).

\section{Kas}

Kas adalah aktiva lancar perusahaan yang bersifat likuid, sehingga saldo kas harus dijaga agar tidak berlebihan uang disebut kas menganggur (idle cash). Kas terdiri dari saldo kas (cash in hand) dan rekening giro. Setara kas (cash equivalent) adalah investasi yang sifatnya sangat liquid, berjangka pendek dan dengan cepat dapat dijadikan sebagai jumlah tertentu tanpa menghadapi resiko perubahan nilai yang signifikan (IAI, 2015).

Kas terdiri dari uang tunai (uang logam dan uang kertas), pos wesel, certifikat check, cashiers' check, cek pribadi, dan bank draft, serta dana yang disimpan di bank yang pengambilannya tidak dibatasi oleh bank atau perjanjian yang lain (Mulyadi dan Kanaka, 2008).

\section{Struktur Organisasi}

Merupakan kerangka (framework) pembagian tanggungjawab fungsional kepada unit-unit organisasi yang dibentuk untuk melaksanakan kegiatan-kegiatan pokok perusahaan, lebih lanjut dipisahkan fungsi-fungsi operasi dan penyimpanan dari fungsi akuntansi. Fungsi operasi adalah fungsi yang memiliki wewenang melaksanakan kegiatan. Fungsi penyimpanan adalah fungsi yang memiliki wewenang menyimpan aktiva perusahaan. Fungsi akuntansi adalah fungsi yang memiliki wewenang untuk 
mencatat peristiwa keuangan perusahaan. Suatu fungsi tidak boleh diberi tanggung jawab penuh untuk melaksanakan semua tahap suatu transaksi (Mulyadi.2016).

\section{Sistem Wewenang}

Dalam organisasi setiap transaksi hanya terjadi atas dasar otorisasi dari pejabat yang berwenang menyetujui terjadinya transaksi sehingga perusahaan membuat sistem pembagian wewenang dengan otorisasi setiap transaksi. Penggunaan formulir harus diawasi dalam rangka pelaksanaan otorisasi, karena formulir merupakan dokumen sebagai dasar pencatatan ke catatan akuntansi. Sistem otorisasi menjamin pembukuan dapat dipercaya dalam proses akuntansi. (Mulyadi, 2016).

\section{Praktek Yang Sehat}

Setiap karyawan dalam perusahaan, melaksanakan tugasnya sesuai pembagian tanggung jawab fungsional, sistem wewenang dengan prosedur yang telah ditetapkan. Dalam praktek yang sehat adanya pelaksanaan penggunaan formulir bernomor urut tercetak, pemeriksaan mendadak, setiap transaksi tidak boleh dilaksanakan satu orang atau satu unit organisasi, perputaran job pekerjaan, cuti karyawan yang berhak, secara periodik dilakukan pencocokan fisik kekayaan dengan catatan (Mulyadi, 2016).

\section{Karyawan Yang Bermutu}

Karyawan yang bermutu adalah pegawai jujur dan ahli bidang tanggung jawabnya untuk melaksanakan pekerjaan secara efisien dan efektif. Karyawan tersebut memiliki kompetensi yang dapat diperoleh melalui seleksi karyawan berdasar persyaratan pekerjaan. Untuk memperoleh karyawan yang mempunyai kecakapan sesuai tuntutan tanggung jawabnya harus dilakukan pengembangan pendidikan karyawan selama menjadi karyawan perusahaan sesuai bidang tuntutan perkembangan pekerjaan (Mulyadi, 2016).

\section{KERANGKA BERPIKIR}

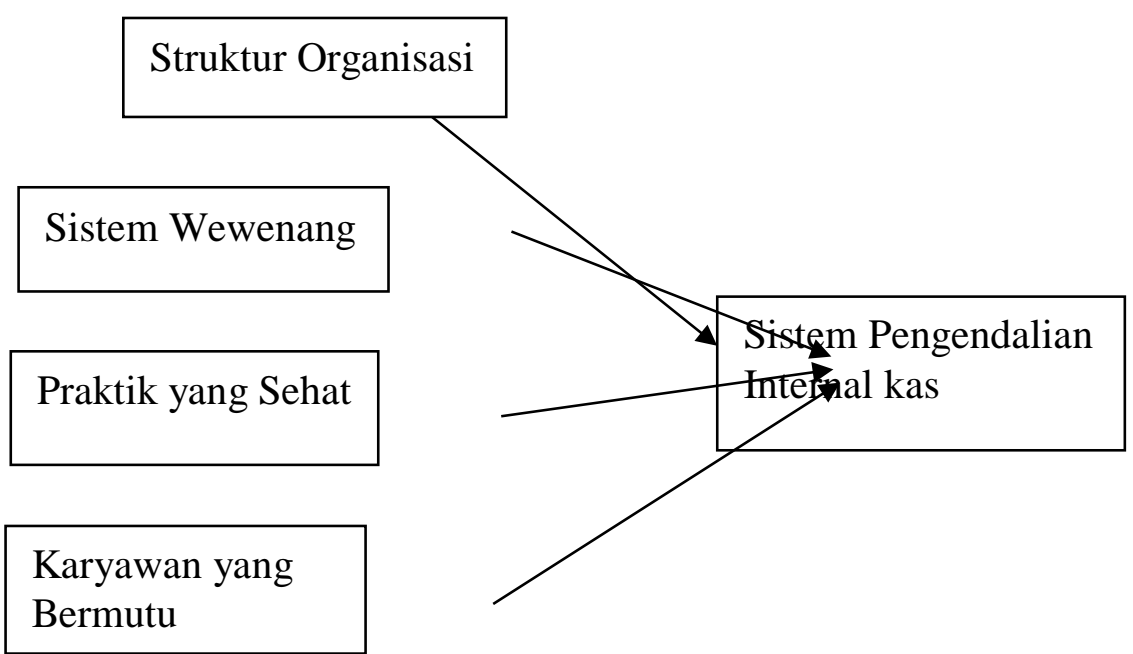




\section{HIPOTESIS}

a. $\mathbf{H}_{\mathbf{1}}$ : Struktur organisasi berpengaruh terhadap sistem pengendalian intern kas.

b. $\mathbf{H}_{2}$ : Sistem wewenang berpengaruh terhadap sistem pengendalian intern kas.

c. $\mathbf{H}_{3}$ : Praktik yang sehat berpengaruh terhadap sistem penendalian intern kas.

d..H4: Karyawan Yang Bermutu berpengaruh terhadap sistem pengendalian intern kas.

\section{METODE PENELITIAN}

Penelitian ini menggunakan pendekatan kuantitatif, pengumpulan data primer dari data wawancara dan kuesioner. Populasi 566 orang karyawan PT. Citra Van Tiki Cabang Solo yang mengikuti rapat setiap bulan. Sampel penelitian menggunakan rumus slovin yang diperoleh sampel sebanyak 85 orang.

Definisi variabel dan Pengukuran Variabel dalam penelitian ini adalah:

1) Struktur organisasi yang memisahkan tanggung jawab fungsional secara tegas.

2) Sistem wewenang dan prosedur pencatatan yang memberikan perlindungan yang cukup terhadap kekayaan, utang, pendapatan, dan biaya.

3) Praktik yang sehat dalam melaksanakan tugas dan fungsi setiap unit organisasi.

4) Karyawan yang mutunya sesuai dengan tanggung jawabnya.

Pengukuran variable penelitian menggunakan skala Likert (Sugiyono, 2016). Tehnik analisis data; 1). Uji validitas 2). Uji asumsi klasik (Ghozali, 2011).

3). Uji Hipotesis regresi linier berganda dengan rumus:

$\mathrm{Y}=\mathrm{a}+\mathrm{b}_{1} \mathrm{x}_{1}+\mathrm{b}_{2} \mathrm{x}_{2}+\mathrm{b}_{3} \mathrm{x}_{3}+\mathrm{b}_{4} \mathrm{x}_{4}+\mathrm{e}$

$\mathrm{Y}=$ Sistem Pengendalian Intern kas

$\mathrm{x}_{1}=$ Struktur organisasi

$\mathrm{x}_{2}=$ Sistem wewenang

$\mathrm{x}_{3}=$ Praktik yang sehat

$\mathrm{x}_{4}=$ Karyawan yang bermutu.

$b_{1} \ldots b_{3}=$ koefisien prediktor persepsi variabel bebas

$\mathrm{e}=$ error

\section{HASIL PENELITIAN}

\section{Uji Validitas}

Critical Value dari 85 responden $(\mathrm{N}=85)$ dengan taraf signifikansi 5\% didapat batasan $\mathrm{r}_{\text {tabel }}: 0,213$.

1). Variabel Struktur Organisasi

Tabel 1. Hasil Uji Validitas Struktur Organisasi

\begin{tabular}{cccc}
\hline $\begin{array}{c}\text { Item } \\
\text { Pertanyaan }\end{array}$ & $\mathrm{r}_{\text {hitung }}$ & $\mathrm{r}_{\text {tabel }}$ & Keterangan \\
\hline X1_1 & 0,507 & 0,213 & Valid \\
X1_2 & 0,701 & 0,213 & Valid \\
X1_3 & 0,688 & 0,213 & Valid \\
X1_4 & 0,685 & 0,213 & Valid \\
X1_5 & 0,609 & 0,213 & Valid \\
\hline
\end{tabular}

Sumber: Pengolahan Data Primer (2020) 
2). Variabel Sistem Wewenang

Tabel 2. Hasil UjiVariabel Sistem Wewenang

\begin{tabular}{cccc}
\hline $\begin{array}{c}\text { Item } \\
\text { Pertanyaan }\end{array}$ & $\mathrm{r}_{\text {hitung }}$ & $\mathrm{r}_{\text {tabel }}$ & Keterangan \\
\hline X1_1 & 0,519 & 0,213 & Valid \\
X1_2 & 0,723 & 0,213 & Valid \\
X1_3 & 0,790 & 0,213 & Valid \\
X1_4 & 0,628 & 0,213 & Valid \\
X1_5 & 0,566 & 0,213 & Valid \\
\hline
\end{tabular}

Sumber: Pengolahan Data Primer (2020)

3). Variabel Praktek Yang Sehat

Tabel 3. Hasil Uji Variabel Praktek Yang Sehat

\begin{tabular}{cccc}
\hline $\begin{array}{c}\text { Item } \\
\text { Pertanyaan }\end{array}$ & $\mathrm{r}_{\text {hitung }}$ & $\mathrm{r}_{\text {tabel }}$ & Keterangan \\
\hline X1_1 & 0,541 & 0,213 & Valid \\
X1_2 & 0,715 & 0,213 & Valid \\
X1_3 & 0,588 & 0,213 & Valid \\
X1_4 & 0,651 & 0,213 & Valid \\
X1_5 & 0,633 & 0,213 & Valid \\
\hline
\end{tabular}

Sumber: Pengolahan Data Primer (2020)

4). Variabel Karyawan Yang Bermutu

Tabel 4. Hasil Uji Variabel Karyawan Yang Bermutu

\begin{tabular}{cccc}
\hline $\begin{array}{c}\text { Item } \\
\text { Pertanyaan }\end{array}$ & $\mathrm{r}_{\text {hitung }}$ & $\mathrm{r}_{\text {tabel }}$ & Keterangan \\
\hline X1_1 & 0,559 & 0,213 & Valid \\
X1_2 & 0,757 & 0,213 & Valid \\
X1_3 & 0,783 & 0,213 & Valid \\
X1_4 & 0,626 & 0,213 & Valid \\
X1_5 & 0,473 & 0,213 & Valid \\
\hline
\end{tabular}

Sumber: Pengolahan Data Primer (2020)

5). Variabel Sistem Pengendalian Internal Kas

Tabel 5. Hasil Uji Variabel Sistem Pengendalian Internal Kas

\begin{tabular}{cccc}
\hline $\begin{array}{c}\text { Item } \\
\text { Pertanyaan }\end{array}$ & $\mathrm{r}_{\text {hitung }}$ & $\mathrm{r}_{\text {tabel }}$ & Keterangan \\
\hline X1_1 & 0,670 & 0,213 & Valid \\
X1_2 & 0,623 & 0,213 & Valid \\
X1_3 & 0,780 & 0,213 & Valid \\
X1_4 & 0,655 & 0,213 & Valid \\
X1_5 & 0,501 & 0,213 & Valid \\
\hline
\end{tabular}

Sumber: Pengolahan Data Primer (2020) 
Uji Reabilitas

Tabel 6. Hasil Uji Reliabilitas

\begin{tabular}{lcll}
\hline \multicolumn{1}{c}{ Variabel } & $\begin{array}{c}\text { Cronbach } \\
\text { Alpha }\end{array}$ & Kreteria & $\begin{array}{l}\text { Keteranga } \\
\mathrm{n}\end{array}$ \\
\hline Struktur Organisasi $\left(\mathrm{X}_{1}\right)$ & 0,637 & $\begin{array}{l}\text { Cronbach } \\
\text { Alpha }>0,6 ; \\
\text { reliabel }\end{array}$ & Reliabel \\
Sistem Wewenang $\left(\mathrm{X}_{2}\right)$ & 0,648 & Reliabel \\
Praktek Yang Sehat $\left(\mathrm{X}_{3)}\right.$ & 0,615 & Reliabel \\
Karyawan Yang Bermutu $\left(\mathrm{X}_{4)}\right.$ & 0,652 & Reliabel \\
Sistem Pengendalian Internal Kas & 0,654 & Reliabel \\
(Y) & & \\
\hline $\begin{array}{l}\text { Sumber: Pengolahan Data Primer }(2020) \\
\begin{array}{l}\text { Dikatakan reliable jika cronbach; } \text { alpha }>0,6 \text { sehingga berdasarkan hasil uji } \\
\text { data dalam penelitian ini reliabel. }\end{array}\end{array}$
\end{tabular}

Asumsi Klasik

Tabel 7. Hasil Uji Normalitas

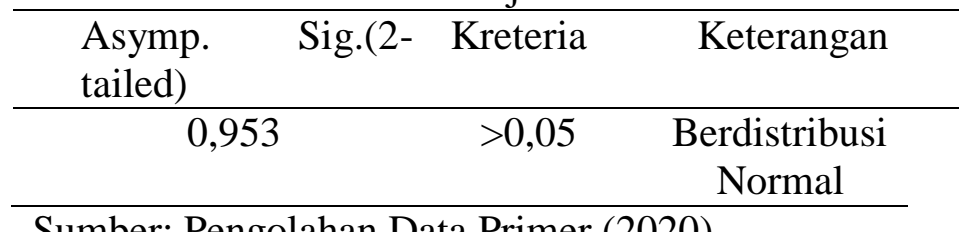

Sumber: Pengolahan Data Primer (2020)

Hasil uji menunjukkan nilai Asymp. Sig. (2-tailed) sebesar 0,953, nilai tersebut lebih besar dari 0,05. maka model regresi dikatakan berdistribusi normal.

Uji Multikolinieritas Tabel 8. Hasil Uji Multikoliniaritas

\begin{tabular}{|c|c|c|c|}
\hline Variabel & Sig. & VIF & Keterangan \\
\hline Struktur Organisasi (X1) & 0,809 & 1,236 & $\begin{array}{l}\text { Bebas } \\
\text { Multikoliniaritas }\end{array}$ \\
\hline Sistem Wewenang (X2) & 0,851 & 1,176 & $\begin{array}{l}\text { Bebas } \\
\text { Multikoliniaritas }\end{array}$ \\
\hline Pratek Yang Sehat (X3) & 0,933 & 1,071 & $\begin{array}{l}\text { Bebas } \\
\text { Multikoliniaritas }\end{array}$ \\
\hline $\begin{array}{l}\text { Karyawan Yang Bermutu } \\
\text { (X4) }\end{array}$ & 0,956 & 1,046 & $\begin{array}{l}\text { Bebas } \\
\text { Multikoliniaritas }\end{array}$ \\
\hline
\end{tabular}

Sumber: Pengolahan Data Primer (2020)

Hasil pengujian menunjukkan bahwa nilai VIF $<10$ dan nilai tolerance $>0,10$, maka dapat dikatakan bahwa tidak terjadi multikolinearitas. 
Uji Heteroskedastisitas

Tabel 9. Hasil uji heteroskedastisitas menunjukkan bahwa nilai Sig>0,05:

\begin{tabular}{|c|c|c|c|}
\hline Variabel & Sig. & Kreteria & Keterangan \\
\hline Struktur Organisasi (X1) & 0,868 & $>0,05$ & $\begin{array}{l}\text { Bebas } \\
\text { Heteroskedastisitas }\end{array}$ \\
\hline Sistem Wewenang (X2) & 0,291 & $>0,05$ & $\begin{array}{l}\text { Bebas } \\
\text { Heteroskedastisitas }\end{array}$ \\
\hline Pratek Yang Sehat (X3) & 0,397 & $>0,05$ & $\begin{array}{l}\text { Bebas } \\
\text { Heteroskedastisitas }\end{array}$ \\
\hline $\begin{array}{l}\text { Karyawan Yang Bermutu } \\
\text { (X4) }\end{array}$ & 0,060 & $>0,05$ & $\begin{array}{l}\text { Bebas } \\
\text { Heteroskedastisitas }\end{array}$ \\
\hline
\end{tabular}

Sumber : Pengolahan Data Pripmer (2020)

Uji Autokorelasi

Tabel 10. Hasil Perhitungan Durbin-Watson

\begin{tabular}{ccclc}
\hline Model & $\mathrm{R}$ & R Square & $\begin{array}{l}\text { Adjusted } \\
\mathrm{R} \\
\text { Square }\end{array}$ & $\begin{array}{l}\text { Durbin- } \\
\text { Watson }\end{array}$ \\
\hline 1 & $.724^{\mathrm{b}}$ & .525 & .501 & 1.840
\end{tabular}

Menggunakan derajat kepercayaan 5\% dengan sampel 85. maka DurbinWatson didapat nilai tabel $\mathrm{d}_{\mathrm{L}} 1.5505$ dan $\mathrm{d}_{\mathrm{U}}$ 1.7470. Nilai DW 1.840 terletak di antara $d_{L}$ dan $d_{U}$ atau $1.5505<1.840<2,253$, sehingga tidak terjadi autokorelasi.

Uji

Hipotesis

Tabel 11. Hasil penelitian Persamaan regresi linier berganda

\begin{tabular}{lcccc}
\hline \multicolumn{1}{c}{ Variabel } & $\mathrm{B}$ & $\mathrm{t}_{\text {hitung }}$ & Sig. & Keterangan \\
\hline (Contanta) & 3,945 & 1,433 & 0,156 & Berpengaruh \\
Struktur Organisasi & 0,454 & 5,719 & 0,000 & Berpengaruh \\
Sistem Wewenang & 0,280 & 3,519 & 0,002 & Berpengaruh \\
Praktek Yang Sehat & 0,181 & 2,295 & 0,024 & Berpengaruh \\
Karyawan Yang & 0,280 & 3,920 & 0,000 & Berpengaruh \\
Bermutu & & & & \\
\hline
\end{tabular}

Sumber : Pengolahan data primer (2020)

Persamaan : $Y=3,945+0,454 X 1+0,280 X 2+0,181 X 3+0,280 X 4+e$

Uji F

Tabel 12. Hasil Uji F

\begin{tabular}{cl}
\hline $\mathrm{F}_{\text {hitung }}$ & Sig. \\
\hline 22,065 & 0,000 \\
\hline
\end{tabular}

Sumber : Pengolahan Data Pripmer (2020) 
Hasil perhitungan dengan menggunakan program bantuan SPSS diketahui besarnya $F_{\text {hitung }}=22,065$, sedangkan nilai $F_{\text {tabel }}=2,71$. Sehingga $F_{\text {hitung }}>$ Ftabel .

Uji T

\begin{tabular}{lcl} 
& Tabel 13 Hasil Uji T \\
\hline Variabel & $\mathrm{t}_{\text {hitung }}$ & $\mathrm{Sg}$. \\
\hline Struktur Organisasi & 5.710 & 0,000 \\
Sistem Wewenang & 3,159 & 0,002 \\
Prakten Yang Sehat & 3,159 & 0,024 \\
Karyawan Yang Bermutu & 3,920 & 0,000 \\
\hline
\end{tabular}

Sumber : Pengolahan Data Pripmer (2020)

Variabel struktur organisasi mempunyai $\mathrm{T}_{\text {hitung }}$ sebesar 5,719> $\mathrm{T}_{\text {tabel }} \quad 1,663$ dengan nilai sig. $0,00<0,05$ yang berarti menolak Ho dan menerima Ha.

Variabel sistem wewenang dan prosedur pencatatan mempunyai $\mathrm{T}_{\text {hitung }}$ sebesar $3,159>\mathrm{T}_{\text {tabel }} 1,663$ dengan nilai sig. $0,02<0,05$ yang berarti menolak Ho dan menerima Ha.

Variabel praktik yang sehat mempunyai $T_{\text {hitung }}$ sebesar 2,295> $T_{\text {tabel }} 1,663$ dengan nilai sig. 0,24<0,05 yang berarti menolak Ho dan menerima Ha.

Variabel karyawan yang bermutu mempunyai $T_{\text {hitung }}$ sebesar 3,920> $T_{\text {tabel }} 1,663$ dengan nilai sig. 0,00<0,05 yang berarti menolak Ho dan menerima Ha.

Koefisien Determinasi

\begin{tabular}{cl} 
& Tabel Hasil Uji Determinasi \\
\hline Adj R $^{2}$ & Keterangan \\
\hline 0,501 & $\begin{array}{l}\text { Presentasi Variabel independent } \\
\text { ke variabel dependen } 50 \%\end{array}$ \\
\hline
\end{tabular}

Sumber : Pengolahan Data Primer (2020).

Hasil uji $\mathrm{R}^{2}$ diperoleh nilai sebesar 0,501 artinya sumbagan pengaruh variabel struktur organisasi, sistem wewenang, praktik yang sehat, dan karyawan yang bermutu terhadap sistem pengendalian intern kas sebesar $50.1 \%$ sisanya sebesar 49,9\% dipengaruhi oleh faktor lain yang tidak dimasukkan dalam penelitian ini.

\section{PEMBAHASAN}

Pengaruh struktur organisasi Terhadap sistem pengendalian internal kas

Pengujian dalam penelitian ini membuktikan bahwa struktur organisasi berpengaruh terhadap sistem pengendalian internal kas baik secara parsial maupun simultan. Dengan demikian struktur organisasi yang memisahkan tanggung jawab secara tegas merupakan kerangka pembagian tanggung jawab fungsional kepada unit organisasi yang dibentuk untuk melaksanakan kegiatan pokok perusahaan. Suatu fungsi tidak boleh diberi tanggung jawab penuh untuk semua tahap transaksi sehingga sistem pengendalian intern mampu menjaga aset organisasi, mengecek ketelitian dan keandalan data akuntansi, mendorong efisiensi, dan mendorong dipatuhinya kebijakan manajemen. Penelitian ini sejalan penelitian dari Sabella (2015) yang menyatakan struktur 
organisasi berpengaruh positif dan signifikan terhadap sistem pengendalian internal kas.

\section{Pengaruh sistem wewenang terhadap sistem pengendalian intern kas}

Pengujian dalam penelitian ini membuktikan bahwa sistem wewenang berpengaruh terhadap sistem pengendalian internal kas baik secara parsial maupun simultan. Dengan demikian dalam organisasi perusahaan otorisasi pejabat yang berwenang menyetujui terjadinya transaksi sangat berpengaruh dan dalam penggunaan formulir harus diawasi sebagai pelaksanaan otorisasi, karena formulir merupakan dokumen dasar pencatatan akuntansi. Sistem otorisasi menjamin pembukuan dapat dipercaya dalam proses akuntansi sehingga sistem pengendalian intern mampu menjaga aset organisasi, mengecek ketelitian dan keandalan data akuntansi, mendorong efisiensi, dan mendorong dipatuhinya kebijakan manajemen. Penelitian ini sejalan dengan penelitian Kencanawati dkk (2014) yang menyatakan sistem wewenang dan prosedur pencatatan berpengaruh positif dan signifikan terhadap sistem pengendalian intern kas.

\section{Pengaruh praktik yang sehat Terhadap sistem pengendalian intern kas}

Hasil pengujian dalam penelitian ini membuktikan bahwa praktik yang sehat berpengaruh terhadap sistem pengendalian internal kas baik secara parsial maupun simultan. Dengan demikian pelaksanaan penggunaan formulir bernomor urut tercetak, pemeriksaan mendadak, setiap transaksi tidak boleh dilaksanakan satu orang atau satu unit organisasi, perputaran job pekerjaan, cuti karyawan yang berhak, secara periodik dilakukan pencocokan fisik kekayaan dengan catatan sehingga sistem pengendalian intern mampu menjaga aset organisasi, mengecek ketelitian dan keandalan data akuntansi, mendorong efisiensi, dan mendorong dipatuhinya kebijakan manajemen. Penelitian ini sejalan dengan penelitian Sabella (2015) yang menyatakan praktik yang sehat berpengaruh positif dan signifikan terhadap sistem pengendalian intern kas

\section{Pengaruh karyawan yang mutunya Terhadap sistem pengendalian internal kas.}

Hasil pengujian dalam penelitian ini membuktikan bahwa karyawan yang bermutu berpengaruh terhadap sistem pengendalian internal kas baik secara parsial maupun simultan. Dengan demikian karyawan yang bermutu memiliki kompetensi mampu melaksanakan bidang pekerjaan sesuai perkembangan pekerjaan sehingga sistem pengendalian intern mampu menjaga aset organisasi, mengecek ketelitian dan keandalan data akuntansi, mendorong efisiensi, dan mendorong dipatuhinya kebijakan manajemen. Penelitian ini sejalan dengan penelitian Susanti (2015) yang menyatakan karyawan yang mutunya sesuai dengan tanggung jawabnya berpengaruh positif dan signifikan terhadap sistem pengendalian intern kas.

\section{KESIMPULAN}

Struktur organisasi, sistem wewenang, praktek yang sehat, dan karyawan yang bermutu berpengaruh terhadap sistem pengendalian intern secara parsial maupun simultan. Dalam struktur organisasi terdapat pemisahan tanggung jawab secara tegas; sistem wewenang terjadi pada pejabat yang berwenang 
menyetujui; praktek yang sehat terlaksana dengan penggunaan formulir bernomor urut cetak dan ada pemeriksaan mendadak; karyawan yang bermutu telah memiliki kompetensi bidang pekerjaannya. Dengan demikian sistem pengendalian intern kas berjalan secara efektif dan tercapainya efisiensi kas perusahaan.

\section{REFERENSI}

Al. Yusup, Haryono. (2011). Dasar-Dasar Akuntansi. Penerbit Sekolah Tinggi Ilmu Ekonomi YKPN. Yogyakarta.

Dewi, Astria, dkk. (2017), Analisis Sistem Pengendalian Itern Kas pada Pt. Jujur Jaya Sakti Makassar, Jurnal Riset Edisi XIII Unibos Makassar, Vol 3, No. 002.

Ferdinand, Augusty. (2011). Metode Penelitian Manajemen. Badan Penerbit Universitas Diponegoro. Semarang

Ghozali, Imam. (2013). Aplikasi Analisis Multivariate dengan Program IBM SPSS 21Update PLS Regresi. Badan Penerbit Universitas Diponegoro. Semarang.

Hidayati, Leny, ( 2015). Analisis Sistem Pengendalian Internal atas Penerimaan dan Pengeluaran Kas pada PT. LMI, E-Journal Fakultas Ekonomi dan Bisnis Jurusan Akuntansi Universitas Narotama Surabaya.

IAI. 2015. Pernyataan Standar Akuntansi Keuangan. Salemba Empat. Jakarta.

Kencanawati, M. S., Prijanto B., Wijiastuti I. (2014). Analisis Sistem Pengendalian Internal terhadap. Penerimaan dan Pengeluaran kas pada Pt. Inti Prima Rasa, Journal S1 Akuntansi Fakultas Ekonomi Universitas Gunadarma, Vol. 8 No. 06.

Mulyani, Sri. (2014). Sistem Informasi Akuntansi, Edisi Kedua. Universitas Terbuka. Tangerang Selatan.

Mulyadi.(2016). Sistem Akuntansi, Edisi Keempat. Salemba Empat. Jakarta.

Mulyadi, Kanaka Puradiredja. (2008). Auditing Edisi Kelima. Salemba Empat. Jakarta.

Purnama, Rico Adetya. 2015. Evaluasi Sistem Pengendalian Intern Pengeluaran Kas Pada CV ENDC.

Sabella, Meidina Azalia. (2015). Analisis Sistem Pengendalian Internal Penerimaan Kas pada PT. Javas Tripta Gemala. 
Pardi, Alisa Rusdiana / Edunomika Vol. 05, No. 01 (2021)

Sugiyono. (2016). Metode Penelitian Bisnis. Alfabeta. Bandung.

Susanti, Eka. (2016). Analisis Sistem Pengendalian Intern Terhadap Sistem Akuntansi Penerimaan Kas pada PT. Jasa Raharja Kantor Perwakilan Bogor. Jurnal Akunida Program Studi Akuntansi Fakultas Ekonomi Universitas Djuanda, Vol.2, No.1. 